\title{
Analisis Seismic Gap Sumatera Menggunakan Anomali Gravitasi
}

\author{
Rahmat Setyo Yuliatmoko' \\ ${ }^{1}$ Puslitbang BMKG, Jl. Angkasa 1 No.2 Kemayoran Jakarta, 10720
}

\begin{abstract}
Abstrak. Informasi mengenai keberadaan seismic gap dapat dilakukan dengan beberapa metode, seismic gap sebelumnya merupakan zona aktif gempa namun sekarang tidak adanya aktivitas gempa, hal tersebut menjadi berbahaya karena adanya penimbunan stress, sehingga jika terjadi gempa maka akan bisa dipastikan gempa yang dihasilkan akan cukup besar. Hal tersebut menjadi perhatian yang serius dalam mitigasi gempa bumi terutama di daerah yang banyak penduduknya. Penelitian ini bertujuan untuk memetakan zona seismic gap dengan data seismik dan dianalisis dengan data anomali gravitasi. Berdasarkan hasil analisis, Berdasarkan hasil analisis, zona seismic gap berada pada zona transisi anomali gravitasi menengah ke rendah hal ini menandakan perbedaan densitas batuan di daerah transisi tersebut dan adanya punggungan bawah laut sehingga daerah tersebut mengalami locking stress. Gaya tekanan dari lempeng maupun dari aktivitas sesar lokal pada batuan tertahan dalam waktu yang cukup lama, sehingga berpotensi terjadinya gempa besar.
\end{abstract}

Kata kunci: gravitasi, seismic gap, locking stress.

\begin{abstract}
Information about the existence of seismic gap can be done by several methods, the seismic gap is the active zone of the earthquake first, but now there is no earthquake activity, this is dangerous because of the pressure build-up so that if an earthquake occurs, it can be ascertained, that the earthquake produced will be quite large. This has become a serious concern in earthquake mitigation, especially in areas with large populations. This study aims to map the seismic gap zone with seismic data and be analyzed with gravity anomaly data. Based on the results of the analysis, the seismic gap zone is in the transition zone of low gravity anomalies, this shows the difference in rock density in the transition area and the existence of underwater mountains so that the area experiences stress locking. The pressure force from the plates and
\end{abstract}

local fault activity on the rock is held long enough, so there is a potential for a large earthquake.

(Keywords: gravity, seismic gap, stress locking)

\section{Pendahuluan}

Seismic gap merupakan daerah bagian dari sesar yang telah menghasilkan gempa bumi di masa lalu tetapi sekarang sunyi tidak menghasilkan gempa bumi, bukan hanya telah diamati secara historis, tetapi diyakini bahwa segmen patahan mampu menghasilkan gempa bumi seperti informasi gerak lempeng atau pengukuran regangan [1].

Dalam ilmu tektonik untuk memahami gempa bumi, gempa bumi terjadi akibat adanya dorongan sebuah lempeng terhadap lempeng yang lain. Stress atau tekanan yang diberikan menghasilkan regangan (strain) atau deformasi pada kawasan pertemuan tersebut. Tekanan yang ada di zona pertemuan lempeng tersebut harus dilepaskan pelan-pelan. Bentuk pelepasan energi tersebut dalam bentuk gempa-gempa kecil. Namun apabila tidak pernah gempa, maka ada kemungkinan terjadi gempa besar.

Seismic gap terindikasi dengan adanya daerah coupling, Konca menggunakan metode perhitungan interplate coupling yang memberikan hasil bahwa di daerah Kepulauan Mentawai, khususnya di Pulau Siberut terjadi full coupling [2].

Penelitian interplate coupling yang dilakukan Febriyani dkk tahun 2014 di daerah Pulau Siberut-Mentawai juga memberikan hasil yang selaras dengan penelitian $\mathrm{M}$. Chlieh tahun 2007 [3][4]. Penelitian tersebut menghasilkan bahwa di daerah Pulau Siberut terjadi fully coupling yang menandakan daerah tersebut mempunyai potensi terjadinya gempa besar di masa datang.

Adanya locking di daerah Jawa diteliti oleh Hanifa dkk pada 2014 melakukan penelitian interplate coupling dan menggunakan 14 stasiun GPS, perhitungan estimasi interpolate coupling [5]. Perubahan 
panjang baseline mengindikasikan pola deformasi interseismic dari bidang subduksi yang terlihat dari pemendekan panjang baseline pada bagian tengah jaring stasiun GPS serta pola deformasi post-seismic pada bagian timur jaring stasiun GPS.

Proses subduksi di bagian selatan Pulau Jawa sebagian besar bersifat aseismic. Dengan demikian, dapat dikatakan bahwa locking antara kedua lempeng bersifat lemah dan pergerakan relatif dari kedua lempeng diakomodasi oleh pergerakan yang kontinu tanpa adanya akumulasi tegangan pada bagian batas kedua lempeng.

Kondisi geologi batuan di bawah permukaan bumi sangatlah komplek karena tidak semua kondisi geologi bawah permukaan mempunyai jenis dan ketebalan batuan yang sejenis. Adanya kompleksitas tersebut disebabkan akibat aktivitas pergerakan di bawah permukaan bumi yang bersifat terus menerus dan dinamis sehingga menyebabkan batuan mempunyai rigiditas atau kekerasan batuan yang berbeda [6].

Rigiditas batuan yang berbeda ini menyebabkan berbeda pula perlakuan tekanan dan regangan stress di batuan. Hal inilah yang mendasari suatu lokasi kadang banyak terjadi gempa ada juga yang jarang terjadi gempa bahkan tidak terdapat gempa. Untuk mendapatkan solusi dari permasalahan tersebut maka secara ilmu geofisika dapat dilakukan melalui metoda gravitasi.

Gravitasi merupakan salah satu metoda geofisika yang digunakan untuk mempelajari kondisi bawah permukaan bumi dengan memanfaatkan sifat kekerasan batuan. Metode gravitasi dapat mendeteksi variasi nilai percepatan gravitasi di bawah permukaan.

Variasi percepatan gravitasi ini disebabkan oleh adanya perbedaan anomali gravitasi akibat variasi densitas batuan di kerak bumi. Variasi nilai densitas batuan di bawah permukaan dipengaruhi oleh adanya variasi litologi batuan secara lateral yang dapat disebabkan oleh berbagai hal, seperti adanya perbedaan lapisan batuan, struktur geologi patahan, lipatan, dan sebagainya.

Pada penelitian ini dilakukan analisis seismic gap di Sumatera dengan metoda gravitasi untuk mengetahui karakteristik batuan di bawah permukaan zona tersebut sehingga terkonfirmasi bahwa daerah tersebut patut untuk diantisipasi dan sebagai langkah mitigasi.

\section{Tatanan Geologi Sumatera}

Sumatera merupakan daerah tektonik yang rumit [7], dimana terdapat konvergensi lempeng India terhadap lempeng Eurasia, dan beberapa sesar aktif dapat dilihat pada gambar 1. Pulau Sumatra merupakan bagian dari lempeng Eurasia yang bergerak dan berinteraksi secara konvergen dengan lempeng Indo-Australia [8].

Zona pertemuan antar lempeng tersebut membentuk zona tumbukan (subduction zone). Zona tumbukan tersebut mengakomodasi pergerakan ke arah utara dari lempeng Indo-Australia terhadap lempeng Eurasia. Aktivitas lempeng Indo-Australia dan Eurasia pada zona subduksi tersebut sering menimbulkan gempa sehingga Pulau Sumatra dianggap sebagai salah satu wilayah tektonik aktif di dunia. [9].

Zona busur muka Andaman-SumatraJawa terbentang lebih dari $4000 \mathrm{~km}$ yang merupakan hasil pertemuan antara Lempeng Indo-Australia dan Lempeng Eurasia. Kecepatan pertemuan lempeng tersebut bervariasi dari $44 \mathrm{~mm} /$ th di bagian Andaman, 60 $\mathrm{mm} / \mathrm{th}$ di selatan Sumatera, dan $68 \mathrm{~mm} / \mathrm{th}$ di selatan Jawa. [10].

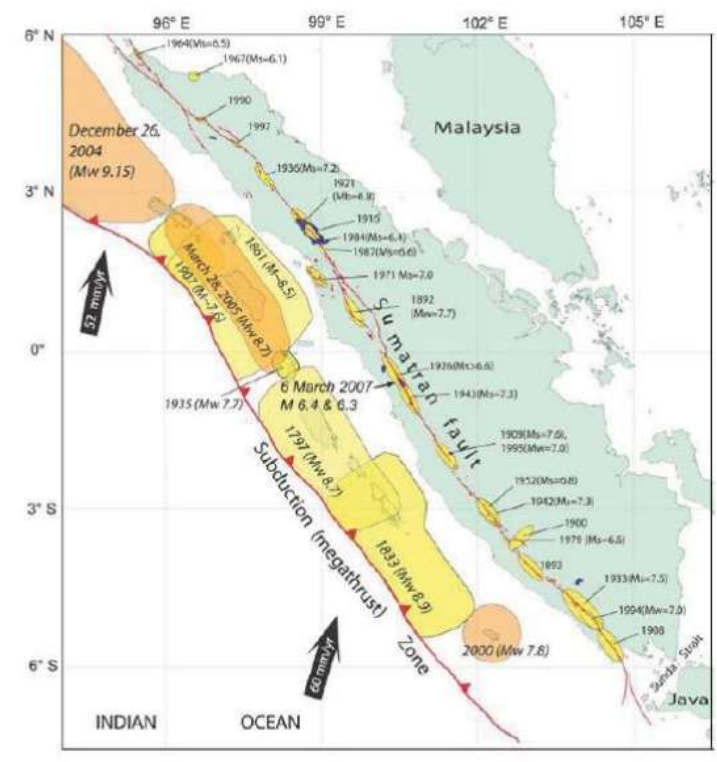

Gambar 1. Sejarah gempa di Sumatera [11].

Di segmen Andaman-Nicobar, subduksi terbentuk sangat miring, dengan sudut $\sim 11^{\circ}$ dari palung. Sebagai hasil dari arah miring, di daerah Laut Andaman [12] konvergensi lempeng diakomodasi oleh Sesar Andaman-Nicobar (Andaman Nicobar Fault disingkat ANF). [13][14] ANF bergabung dengan pusat pemekaran di Laut Andaman (Andaman Sea Spreading Center, disingkat ASSC) dan kemudian menghubungkan dengan Sesar Sagaing (SaF) di Myanmar [15].

\section{Metode Penelitian}

Metode gravitasi didasari oleh prinsip fisika menurut hukum Newton mengenai 
interaksi antara dua partikel dengan massa yang terpisah sejauh jarak tertentu.

Hukum gravitasi Newton menyatakan apabila $F$ adalah nilai gaya gravitasi, $G$ konstanta gravitasi universal $\left(6.67 \times 10^{-11}\right.$ $\left.\mathrm{km}^{3} \mathrm{~kg}^{-1} \mathrm{~s}^{-2}\right), m_{1}$ dan $m_{2}$ adalah massa. $r$ adalah jarak; dan $r$ adalah unit vektor pada arah koordinat $r$ yang berasal dari pusat massa, maka nilai gaya gravitasi dapat dinyatakan menurut persamaan berikut [16]:

$F=-G \frac{m_{1} m_{2}}{r^{2}} r^{\wedge}$

Nilai percepatan gravitasi pada setiap titik pengukuran gravitasi setidaknya dipengaruhi oleh faktor posisi pengukuran pada garis lintang, ketinggian titik ukur, posisi bulan dan matahari, topografi di sekitar titik pengukuran, anomali batuan di bawah permukaan [17].

Anomali gravitasi udara bebas adalah nilai percepatan gravitasi yang sudah tidak dipengaruhi oleh posisi garis lintang, ketinggian titik ukur, serta posisi bulan dan matahari. Anomali gravitasi udara bebas didapatkan dengan mengoreksi nilai gravitasi observasi dengan anomali bouguer.

Penelitian ini dilakukan dengan menggunakan data gempa dan gravitasi. Data gravitasi udara bebas (FAA) didapatkan dari TOPEX, selanjutnya dihitung bouger anomalinya dan ditentukan simple anomali bougernya kemudian dilakukan ploting [18].

Anomali gravitasi udara bebas dapat digunakan untuk analisis pada area regional dengan baik sehingga cocok digunakan untuk penelitian secara regional di Pulau Sumatera [19]. Data gempa untuk menentukan seismic gap diperloleh dari BMKG dan IRIS dimulai dari tahun $1969-2019$ [20].

\section{Hasil dan Pembahasan}

Seismic gap dapat dilihat dari seisimisitas gempabumi maka dari hasil ploting seismisitas Sumatera dengan kedalaman yang beragam, target seismic gap dapat terlihat yang ditandai dengan balok warna kuning.

Berdasarkan data yang didapatkan dari BMKG dan IRIS telah mencatat ada 1414 event gempa di sekitar Pulau Sumatera sejak 1 januari 1969 hingga 1 September 2019 dan ditampilkan pada Gambar 3.

Titik pusat gempa atau episentrum gempa tersebar di sepanjang Pulau Sumatera terkonsentrasi di laut Barat Sumatera ada juga di darat tempat sesar Semangko berada. Hal ini dikarenakan bagian Barat Pulau Sumatera merupakan zona subduksi antara lempeng Indo-Australia dengan lempeng Eurasia.
Seismic gap yang terdeteksi berada di zona Mentawai.

Berdasarkan sumbernya, gempa bumi dapat disebabkan oleh tumbukan lempeng pada zona batas tektonik atau pergerakan patahan pada batuan. Sesuai dengan tujuan dari penelitian ini, zona seismic gap pada gambar 3 satu seismic gap di kepulauan Mentawai akan dianalisis lebih lanjut dengan data gravitasi.

Data anomali gravitasi yang didapatkan dari TOPEX dipetakan dengan SURFER ditampilkan pada Gambar 2. Penelitian ini menggunakan data anomali gravitasi udara bebas dengan dilakukan pengolahan lebih lanjut sehingga didapatkan anomali bouger.

Secara keseluruhan, terlihat bagian Barat hingga Timur Pulau Sumatera memiliki nilai anomali gravitasi yang relatif beragam dari -200 sampai 696 mGal (Gambar 2).

Nilai anomali gravitasi tinggi di sebelah Barat Sumatera antara $400-600 \mathrm{mGal}$ hal ini dikarenakan lempeng Samudera Indo-Australia memiliki densitas batuan yang lebih tinggi jika dibandingkan densitas batuan lempeng Eurasia.

Sedangkan bagian Timur memiliki nilai 400-(-200) mGal hal ini mengindikasikan bahwa lempeng Eurasia memiliki densitas yang lebih rendah jika dibandingkan dengan daerah subduksi terlihat jelas di data batimetri, di sebelah Barat Sumatera terdapat lipatan dan pegunungan karena adanya benturan dua lempeng yang berbeda densitasnya terlihat juga perbedaan anomali gravitasi di daerah subduksi dengan degrade warna merah hingga hijau. 

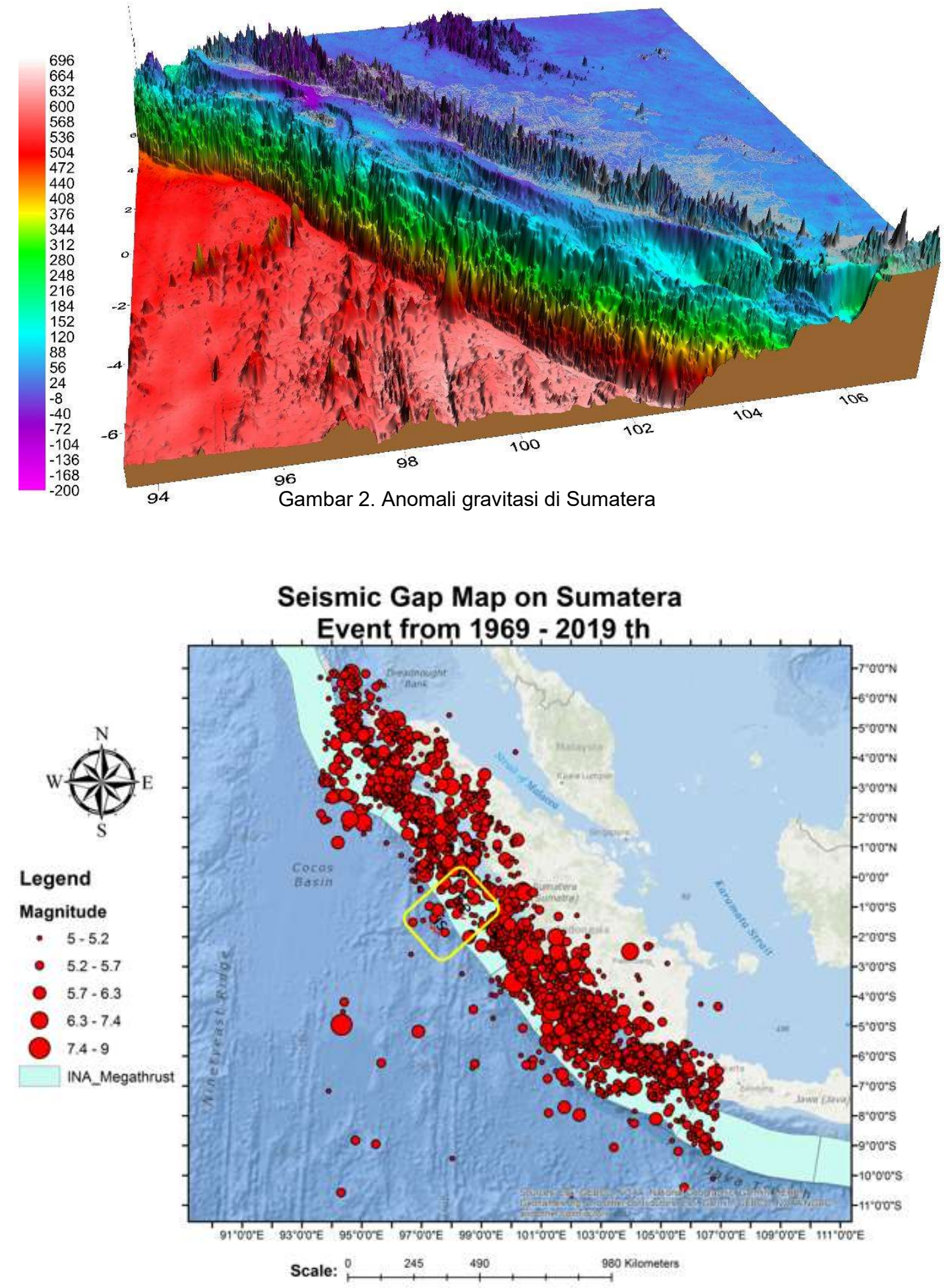

Gambar 3. Seismic Gap di Sumatera 
Seismic gap di Sumatera pada gambar 6 ditandai dengan kotak warna kuning. Setelah di zoom gambar 6 sebelah kanan berdasarkan data batimetri terdapat gugusan pegunungan bawah laut yang berjajar ke arah Timur dengan anomali gravitasi besar 300 sampai $400 \mathrm{mGal}$ yang menandakan terdapat variasi anomali gravitasi dengan densitas batuan yang beragam, oleh karena itu daerah tersebut terdapat locking atau kuncian energy gaya dorong lempeng samudera Indo-Australia. Adanya locking di daerah tersebut juga didukung oleh beberapa penelitian diantaranya [4], dengan menggunakan data geodetik dan paleogeodetik.

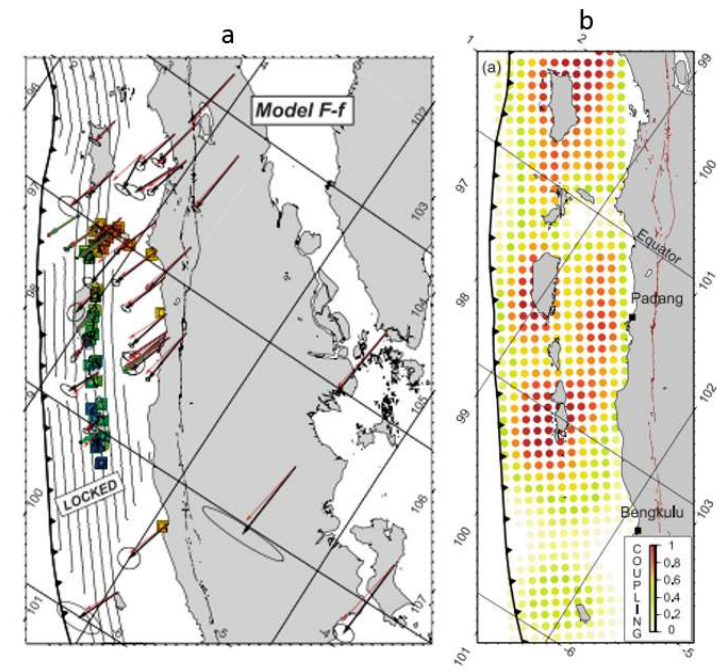

Gambar 4. Locking di Kepulauan Mentawai [4]
Pada gambar 4 terlihat adanya locking pada sekitar kepulauan Mentawai full locked dengan ditandai tidak adanya pergerakan slip warna hijau. Sedangkan untuk gambar 5 untuk locked terindikasi di sekitar kepulauan Mentawai pulau Batu Sipora dan Enggano ditandai dengan warna merah.

Fitur unik dari area Kepulauan Mentawai ditandai dengan adanya zona gap seismik yang merupakan area gempa historis pada tahun 1797 dengan zona rupture di seluruh Kepulauan Mentawai dan 1833 yang terjadi di bagian selatan Mentawai [14].

Kondisi coupling yang tinggi di zona gap Mentawai belum dilepaskan oleh gempagempa yang signifikan di sekitar area ini seperti gempa 2007, gempa Padang Mw 7.9 tahun 2009, dan gempa Mentawai Mw 7.8 tahun 2010 [12].

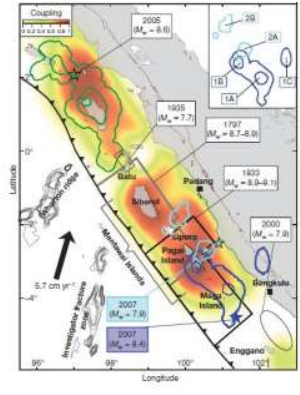

(a)

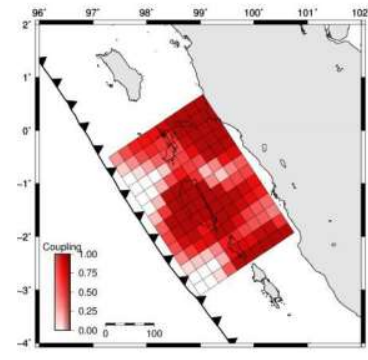

(b)
Gambar 5. Locking di Kepulauan Mentawai [2][3].

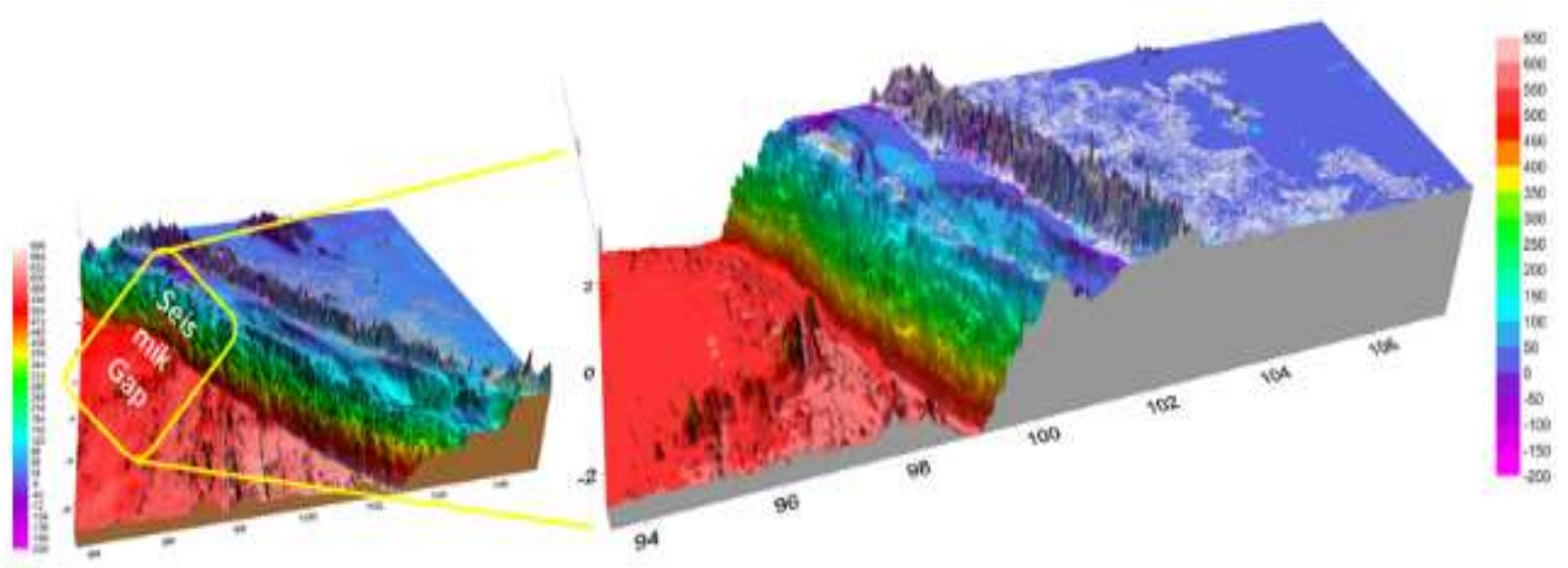

Gambar 6. Seismic gap dan anomali gravitasi di Sumatera 
Beberapa gempa dengan Mw > 6 juga terjadi di area timur Pulau Siberut dengan mekanisme sesar naik yang berkaitan dengan backthrust Mentawai (MBT) sehingga pengaruh gempa-gempa ini terhadap segmen Mentawai perlu diteliti lebih lanjut. Gempa Padang tahun 2009 merupakan gempa intraslab dengan mekanisme oblique [12].

Konca menggunakan metode perhitungan interplate coupling (Gambar 5a) yang memberikan hasil bahwa di daerah Kepulauan Mentawai, khususnya di Pulau Siberut terjadi full coupling.

Penelitian interplate coupling yang dilakukan Febriyani dkk tahun 2014 (Gambar 5b) di daerah Pulau Siberut-Mentawai juga memberikan hasil yang selaras dengan penelitian M. Chlieh, (2007). Penelitian tersebut menghasilkan bahwa di daerah Pulau Siberut terjadi fully coupling yang menandakan daerah tersebut mempunyai potensi terjadinya gempa di masa datang.

\section{Kesimpulan}

Berdasarkan hasil analisis, zona seismic gap berada pada zona transisi anomali gravitasi menengah ke rendah hal ini menandakan perbedaan densitas batuan di daerah transisi tersebut dan adanya punggungan bawah laut sehingga daerah tersebut mengalami locking stress. Gaya tekanan dari lempeng maupun dari aktivitas sesar lokal pada batuan tertahan dalam waktu yang cukup lama, sehingga berpotensi terjadinya gempa besar.

\section{Ucapan Terima Kasih}

Memberikan penghargaan kepada IRIS dan BMKG yang telah memberikan data sehingga dapat memperlancar dalam proses penulisan makalah ini.

\section{Daftar Pustaka}

[1] USGS Earthquake Glossary (2019). https://earthquake.usgs.gov/learn/glossa ry/?term=seismic\%20gap, diakses 10 September 2019.

[2] Konca, A. O., Avouac, J. P., Sladen, A., Meltzner, A. J., Sieh, K., Fang, P., ... \& Helmberger, D. V. (2008). "Partial rupture of a locked patch of the Sumatra megathrust during the 2007 earthquake sequence". Nature, 456(7222), 631-635.

[3] Febriyani, C. (2015). Interplate Coupling Beneath Siberut Island. Tesis Program Magister Teknik Geodesi. Institut Teknologi Bandung.

[4] M. Chlieh, (2007) Heterogeneous Coupling of the Sumatran Megathrust
Constrained By Geodetic and Paleogeodetic Measurements. Journal of Geophysical Research, Vol. 113, B05305, Doi: 10.1029/2007jb004981, 2008.

[5] Hanifa, N. R. (2014). Interplate Earthquake Potential off Western Java, Indonesia, based on GPS data. Doctoral Dissertation of Nagoya University, Japan.

[6] Lowrie. 2007. Fundamentals of Geophysics, Second Ed. New York: Cambridge University Press.

[7] Bemmelen, R.W. Van., 1949. The Geology of Indonesia, Vol. 1 A, (Government Printing Office), the Hauge.

[8] Bock (2003): Crustal Motion in Indonesia from Global Positioning System Measurements, Journal of Geophysical Research, Vol. 108, No. B8, 2367, Doi: 10.1029/2001jb000324, 2003.

[9] McCa_rey.R, 2009. The Tectonic Framework of the Sumatran Subduction Zone, Earth and Environmental Sciences, Rensselaer Polytechnic Institute, Troy, New York.

[10] DeMets, C., Gordon, R. G., dan Argus, D. F, 2010. Geologically current plate motions, Geophysical Journal International, 1, 1-80.

[11] Natawidjaja, D. H., and W. Triyoso, 2007. The Sumatran Fault Zone-From Source to Hazard, J. Earthq. Tsunami, 1(01) 2147.

[12] McCloskey, J., Lange, D., Tilmann, F., Nalbant, S.S., Bell, A.F., Natawidjaja, D.H. and Rietbrock, A., 2010. The September 2009 Padang earthquake. Nature Geoscience, 3(2), pp.70-71.

[13] Singh, S. C., R. Moeremans, J. Mcardle, and K. Johansen, 2013. Seismic Images of the Sliver Strike-Slip Fault and Back Thrust in the Andaman-Nicobar Region, J. Geophys. Res. 118. 1-17, Doi:10.1002/Jgrb.50378.

[14] Sieh, K., D. H. Natawidjaja, A. J. Meltzner, C.-C. Shen, H. Cheng, K.-S. Li, B. W.

[15] Vigny, C., A. Socquet, C. Rangin, N. Chamot-Rooke, M. Pubellier, M.-N. Bouin, G. Bertrand, and M. Becker, 2003. Present-Day Crustal Deformation around Sagaing Fault, Myanmar, J. Geophys. Res., 108, 2533.

[16] R. J. Blakely, 1996. Potential Theory in Gravity \&Magnetic Applications. Cambridge: Cambridge University Press.

[17] Abercrombie, R.E., Antolik, M., Felzer, K. \& Ekström, G. (2001). The 1994 Java 
tsunami earthquake: Slip over a subducting seamount. J.Geophys. Res. 106(B4), 6595-6607.

[18] TOPEX.Internet: https://topex.ucsd.edu /cgi-bin/get_data.cgi diakses pada 11 September 2019

[19] N. A. Ferani, E. Hartantyo, and S. W. Niasari. Spatial Analysis of Gravity Data in the California, Nevada, and Utah (US), Journal of Physics:Conference Series, vol. 1011, no. 1, pp.0-5, 2018.

[20] BMKG Earthquake Repository (2019). http://repogempa.bmkg.go.id, diakses 10 September 2019. 